\title{
System based on piezoelectric sensors for deflection measurement in concrete beams
}

\section{Sistema basado en sensores piezoeléctricos para la medida de la flecha en vigas de hormigón}

Daniel Ferrández Vega (Main Autor)

Departamento de Ingeniería de Organización, Administración de Empresas y Estadística

Universidad Politécnica de Madrid

28660 Boadilla del Monte, Madrid (Spain)

daniel.fvega@upm.es

Carlos Morón Fernán dez (Corresponding Autor)

Departamento de Tecnología de Edificación, Universidad Politécnica de Madrid

Avenida Juan de Herrera, 6, 28040, Madrid (Spain)

carlos.moron@upm.es

\section{Pablo Saiz Martínez}

Departamento de Economía Financiera, Contabilidad e Idioma Moderno

Universidad Rey Juan Carlos

Paseo de los Artilleros, 28032 Madrid (Spain)

pablo.saiz@urjc.es

\section{Jorge Pablo Díaz Velilla}

Departamento de Tecnología de Edificación, Universidad Politécnica de Madrid Avenida Juan de Herrera, 6, 28040, Madrid (Spain)

jdiaz@salesianoscarabanchel.com

Manuscript Code: 1221

Date of Acceptance/Reception: 14.07.2019/26.11.2018

DOI: 10.7764/RDLC.18.2.282

\begin{abstract}
Activity of static loads and different activities of dynamic loads produced over the structure of a building have a negative effect causing deformations of the materials that form the structure. Reinforced concrete is the most used in building structural material, being deflection its most important deformation that affects bending elements fabricated with this material. This paper presents a new measurement system based on the response of a piezoelectric low cost sensor. Placing the device in the midspan of the beam where maximum deformation is produced, the sensor is able to collect deflection variations according to the loads the element is subjected to, showing produced variations in real time.
\end{abstract}

Key words: piezoelectric sensor, deflection, concrete, detection system.

Resumen

La acción de las cargas estáticas y de las distintas acciones dinámicas que se producen sobre la estructura de un edificio tienen un efecto nocivo produciendo deformaciones en los materiales que las componen. El hormigón armado es el material estructural más empleado en edificación, siendo la flecha la deformación más importante que se produce en los elementos a flexión elaborados con dicho material. En este trabajo, se presenta un nuevo sistema de medida basado en la respuesta que ofrece un sensor piezoeléctrico, de tal forma, que al situar el dispositivo implementado en el centro de una viga apoyada donde se produce la máxima deformación, éste es capaz de recoger las variaciones producidas en la flecha en función de las cargas a las que se encuentra sometido el elemento, monitorizando a tiempo real el edificio en estudio.

Palabras clave: sensor piezoeléctrico, flexión, hormigón, sistema de detección.

Introduction

In terms of studying deformations of structural elements, transverse movements to the directive of the beam are the most harmful for the building as they cause cracking in partitions and walls initially intended to support only their own weight and coating projected in them (García et al., 2011). These pathologies caused by the action of deflection generated in beams are nowadays the reason of a big part of lawsuits against the professionals of the construction sector (Gil \& Mas, 2015).

There are a lot of researches about the determination of deflection produced in concrete structures. Some authors center their investigations in final prediction of deflection according to the time during which the load acts and according 
to the age of the concrete in the moment of applying the load, in order to identify the maximum admissible deformations that the material can support (Un et al., 2015). Other authors study the influence of new reinforcement materials on structures and how they improve their bending characteristics decreasing deflection (Lapko \& Urbariski, 2015), however sometimes working with some recycled materials, these deformations are higher compared to the original element being necessary to know them (Mohamed, 2017). Nevertheless, all these applications require equipment to check their efficiency and also to calculate the improvement in real time.

The problem of measuring evolution of deflection is produced measuring the movement of the midspan of the concrete beam on two supports. For this, there are different sensors and measuring devices that allow to carry out this function. On the one hand, there are capacitive sensors that keeping fixed their geometry and distance between condenser plates, offer an electric response that is the function of the dielectric placed between the plates, detecting in this way the variations that are produced in it (Morón et al., 2014). Other authors use for the deflection measurement in structural element the Wheatstone bridge method, measuring the difference in the tension produced between both branches of the bridge, when this is unbalanced because of the application of the load that deploys the effort (Vignolo \& Vázquez, 2012). Those are deflection measuring devices of high gain and limited thermal drift that can be placed in parallel on studied structural element. Resistive sensors with extensiometric gauges based on the resistance variation of a conduit subjected to mechanical stress are widely used in building because of their easy installation (Payo \& Feliu, 2014). There are also papers that study magnetoelastic sensors based on the Villari effect, studying changes produced in magnetic curves when ferromagnetic material is deformed (Ausanio et al., 2005).

More precisely, in case of piezoelectric sensors some authors performed studies to monitor structures in order to identify damages in concrete through electromechanical admission techniques (Providakis et al., 2013). These monitoring techniques allowed to detect structures damages through the variation of electric admittance with the help of piezoelectric sensors placed on the surface. Piezoelectric sensors situated in cracking area in supported concrete beams presented higher sensibility and easy application in its whole frequency range than other commercial sensor. This allows to use this devices for evaluation of hidden damages in reinforced concrete structures (Karayannis et al., 2015).

Nevetheless, not all of the studies focus on beam flexure measurement, some authors used piezoelectric sensor to monitor tensile compression in concrete structures, obtaining results that can be used to reassure the structural security in construction (Ai et al., 2018).

These piezoelectric sensor can be also used in terms of structural security in areas of high seismic activity, being able to determine in real time cracking state of reinforced concrete pillars (Kong et al., 2016). Others authors developed systems based on network of remote control piezoelectric sensors that can predict through voltage variations the beginning diagonal cracking produced in concrete structures (Voutetaki et al., 2016); these systems with loT techniques allows to visualize in real time in mobile devices the state and evolution of building cracks.

This paper is dedicated to developing a novel measuring system based on the low cost piezoelectric sensor that situated properly on the central part of the element subjected to flexural stress is able to detect deformation variations produced under the action of a continuous load. In this way, it can be implemented in the buildings at risk of collapse presenting excessive deflection or that need to be monitored because of their typology.

\section{Methodology}

This part describes the materials that were used to fabricate tested specimens, and the design of the measuring system and its theoretical basis.

\section{Materials}

To carry out the research, two well differentiated concretes were used, one can be considered to be of high resistance and another of medium resistance and commonly used in building, with an idea to detect significant variations of deflection produced in both. Used dosages in weight are shown in Table 1.

Table 1. Dosages used for the implementation of concretes. Source:

\begin{tabular}{cccccc}
\hline Denomination & Dosage & Cement $(\mathrm{kg})$ & Water $(\mathrm{kg})$ & Aggregate $(\mathrm{kg})$ & Gravel $(\mathrm{kg})$ \\
\hline $\mathrm{HM}-25^{*}$ & $1-2-3-0.6$ & 8 & 5 & 16 & 24 \\
$\mathrm{HM}-40^{*}$ & $1-1-2.5-0.5$ & 10 & 5 & 10 & 25 \\
\hline
\end{tabular}

*Consistency according to the standard UNE-EN 12350-2:2009 (UNE, 2009a). 
Both concretes were prepared according to the requirements of the standard UNE-EN 12390-2:2001 (UNE, 2009b) and cured at the same temperature and humidity in moisture chamber during 28 days.

\section{Theoretical basis}

Resistance of concrete to traction plays a fundamental role while determining cracking produced in the lower surface of simply supported beams. It is difficult to determine this resistance by conventional tests, being more practical to determine this indirectly through the test of flexotraction established by the standard UNE-EN 12390-5:2009 (UNE, 2009c).

For this, prismatic specimens of $10 \times 10 \mathrm{~cm}^{2}$ square-section and $60 \mathrm{~cm}$ long were fabricated. Specimens are supported in a way that the load is applied occasionally and at constant speed to the centre of the specimen. The mechanism to apply the load consists in a steel roller of $20 \mathrm{~mm}$ diameter that descends slowly over one of the surfaces that initially was in contact with the form, avoiding in such a way surfacing of specimens and possible heterogeneities.

Deformations and deflection calculations are carried out basing on the characteristic values of the actions and on concrete resistance, as the aim is to know the behaviour of the structure. Resistance of the material allows to calculate deflection of a beam of constant inertia with linear and symmetric material with respect to the load showed in the following expression:

$$
f=\alpha \cdot \frac{M_{a} \cdot l^{2}}{E \cdot I}(m m)
$$

where $\alpha$ is a coefficient depending on the type of load and support (Figure 1.a), $M_{a}$ is bending moment acting in the reference section, $l$ is the light of the beam, $E$ is the modulus of deformation of material and $I$ is inertia moment of transversal section.

However, in case of concrete rigidity is not constant, due to the fact that along the beam on two supports there are different inertias, some of them are cracked and another are not, that is why the standard EHE-08 (R.D. 1247, 2008) proposes the following expression to calculate equivalent inertia:

$$
I_{e}=\left(\frac{M_{f}}{M_{a}}\right)^{3} \cdot I_{b}+\left[1-\left(\frac{M_{f}}{M_{a}}\right)^{3}\right] \cdot I_{f} \ngtr \cdot I_{b} \quad\left(m^{4}\right)
$$

where $M_{f}$ is a bending moment of cracking, $M_{a}$ is acting service cracking moment, $I_{b}$ is a moment of inertia of gross rectangular section of concrete and $I_{f}$ is a moment of inertia of cracked section.

Figure 1: (a) Parameters of bending beam; (b) Simulation of stress with FreeCAD. Source: Authors' own elaboration.

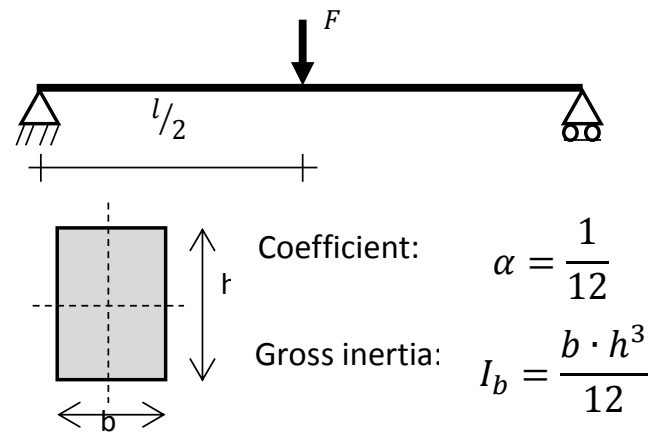

(a)

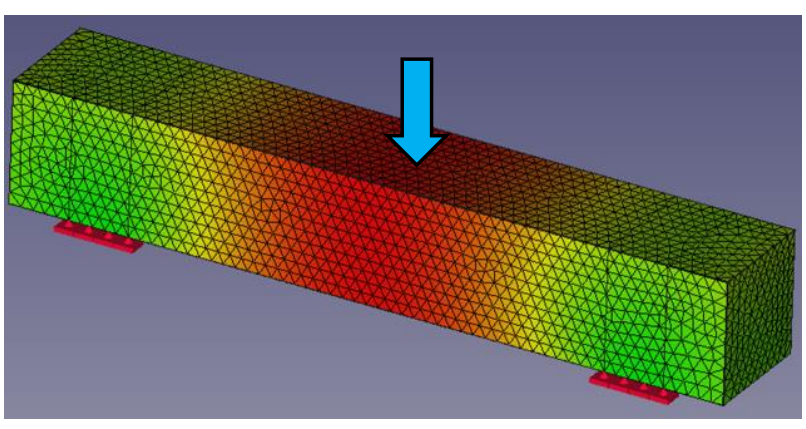

(b)

As it can be observed in the simulation shown in Figure 1.b, after the simulation of expected behaviour of bending beam the highest stress is produced in the lower surface of the specimen, exactly at the mid distance between the supports. 


\section{Measuring device}

Prototype of measuring device can be seen in Figure 2 and consists in a piezoelectric sensor situated on the lower surface of the specimen, electronics of designed circuit, power supply unit and an oscilloscope to assess the response of the sensor. It should be stressed that the measurements presented in this paper have been collected only with a help of the developed device. Future research can be dedicated to the comparative analysis using LVDTs or DTs sensors. This device can measure elastic flexural strength in supported concrete beams, as in case of the test of flexural strength in three points.

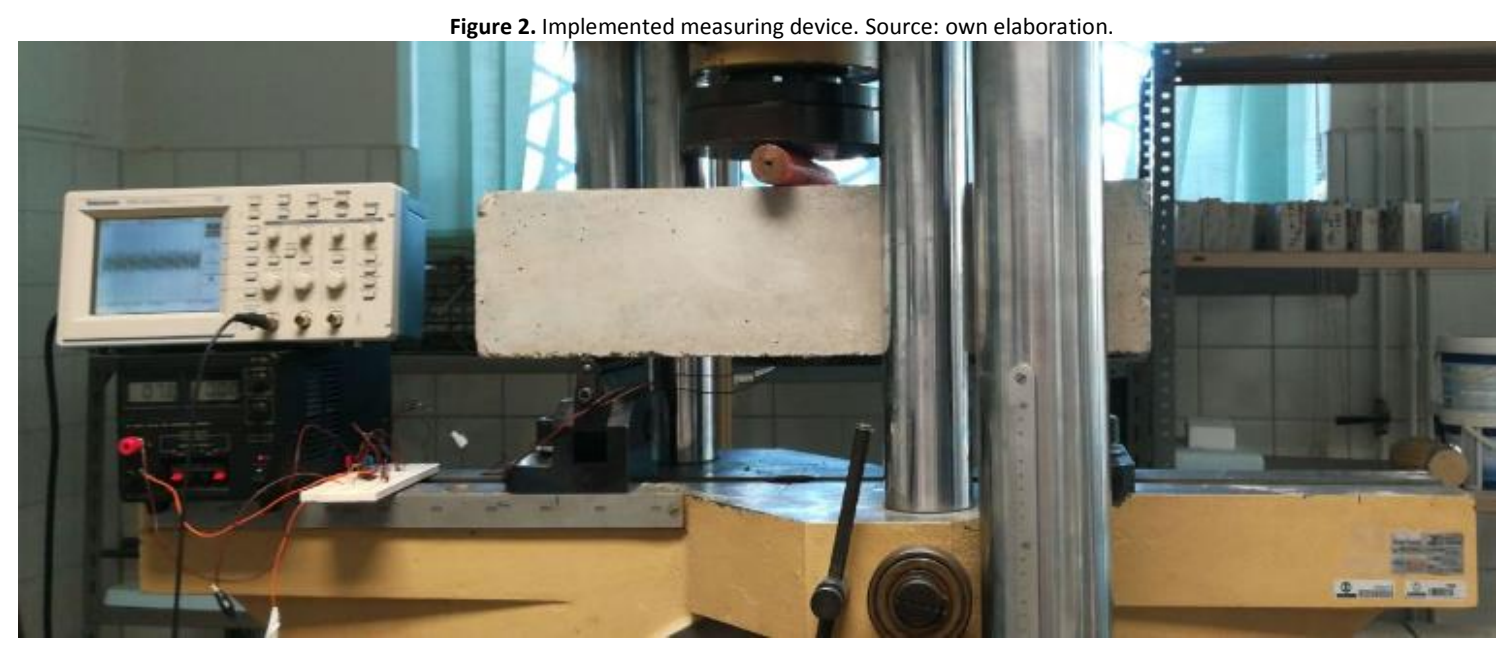

As it can be seen in Figure 2, the flexural strength is measured in three points, where the concrete beam is supported and submitted to the point load in the midspan. Piezoelectric sensor is placed on the inferior face of the beam and converts deflections into current outputs in electronic circuit alimented by a power source. Oscilloscope can be also observed in the figure. It was used to adjust the measurements collected by the sensor during the design phase.

\section{Sensor design}

It was decided to use a piezoelectric sensor for the development of the measuring system. Moreover, working under environment conditions there is no risk to exceed Curie temperature proper for piezoelectric material, and applying the load continuously and in a controlled manner frequency response of the sensor does not present high peaks caused by the resonance. Furthermore, its low cost and high mechanic rigidity makes this type of piezoelectric sensor more competitive taking into account also its reduced dimensions and unidirectional sensitivity what is very important for deflection measuring in beams (García et al., 2017).

As it is shown in Figure 3, the circuit consists in various stages. Firstly, the sensor LDT0-028K is situated in the midspan of the beam. The deflection caused by the load makes the ions that formed piezoelectric film to change the position, originating in this way electric dipoles that generate electric signal. This signal is collected and regulated by the previously calibrated variable resistances that filter the signal sent to the amplifier to be interpreted by the encoders. These sensors sent the logical response that should be intelligible by the screens showing flexural value for a determined time value before the decoding.

Thus, the application of this of systems allowed to change from the traditional functioning model to measure beam deflection based on the visual inspections and measure directly on the span to the model where the response and detection are integrated. Moreover, the piezoelectric detector is an energy efficient system of passive detection with advantage to be used in the construction sector allowing to measure changing pressures according to the structural state of the building.

On the other hand, the presented prototype could modify one of its stages from analogical to digital to reduce the size if it is necessary. Nevertheless, to be used in the laboratory this option has advantage to replace components in case of failure. 


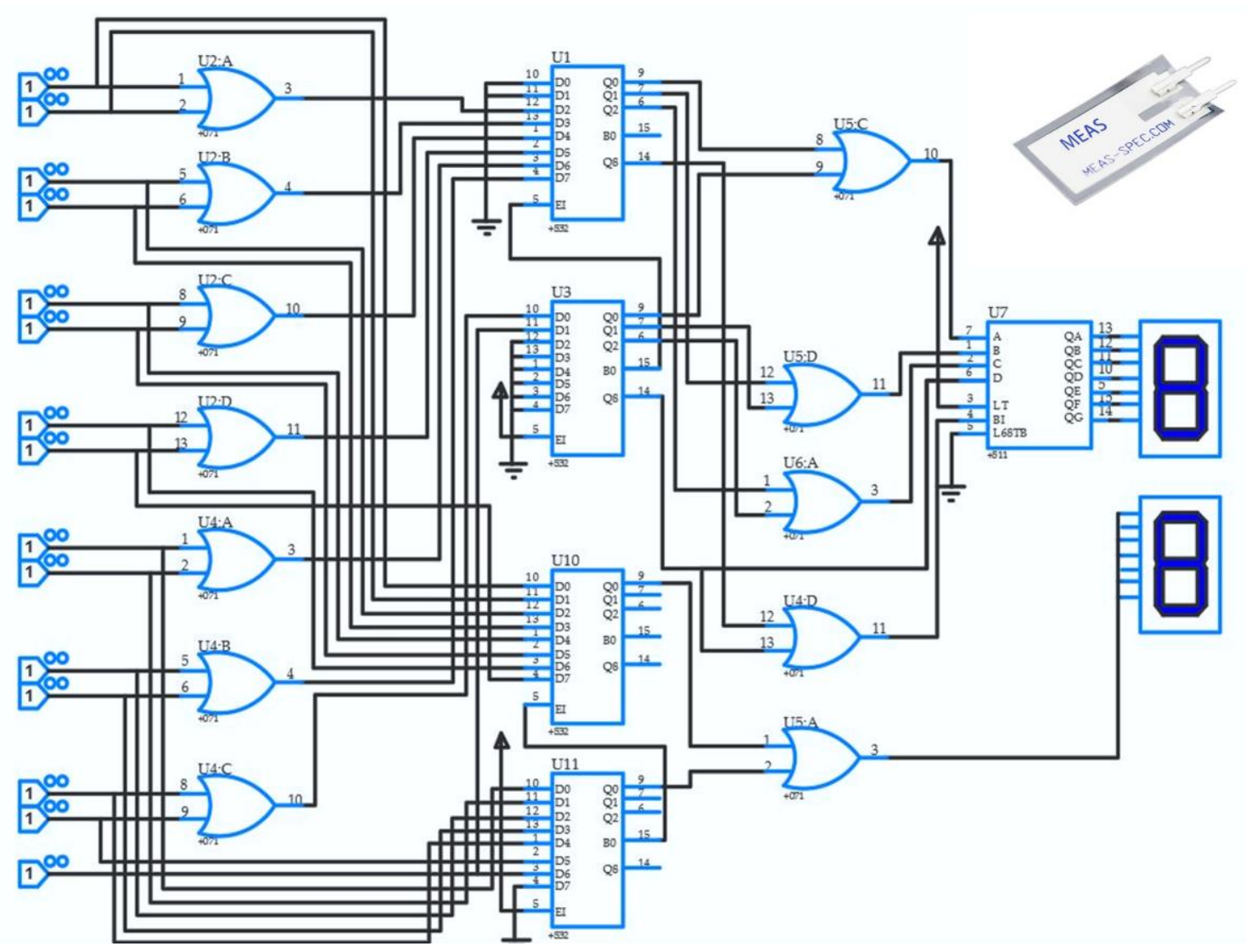

Among the components shown in Figure 3, there are logic gates encapsulated into CD4071B chip with symmetric and standardized signal output, that receive the signal of the sensor in excitation. Output of these gates is received in codifying stage where codifiers of CD4532B model are used, which establish a preference order in binary codification, using floating point variables. Finally, the signal passes to the phase of decoding where the chip CD74HC4511 is located, which enables/disables, decode and amplify (latch, decoder and drivers respectively) the signal to represent lately the value of deflection in $\mathrm{mm}$ in displays of eight segments. These type of CMOS decoders are of low energy consumption compared with systems based on TTL logic.

Results

Results derived from the carried out tests can be divided in two parts. On the one hand, there is a relation between the load exerted over specimens subjected to the test of flexural and the deflection produced in them, as it can be observed in Figure 4. As it can be observed, the load applied to reach the rupture is higher in HM-40 than in HM-25 in accordance with used dosages.

As it can be observed in both cases, the relation is linear with a very high correlation in a way that when the major load is exerted over the specimen, the deflection increases. Vertical deformation reaches values no superior to $5 \mathrm{~mm}$ in case of $\mathrm{HM}-25$ and around $8 \mathrm{~mm}$ for $\mathrm{HM}-40$, in accordance with the theoretical predictions. Both deflections are within the range measurable by the sensor allowing to offer a linear response as shown in Figure 5.

In Figure 5 it can be observed how the response of the sensor in voltage is practically linear for the reached values of deformation, what allows to calibrate the device for its possible implementation into real buildings avoiding areas of saturation within considered interval. This response varies between 0 and $14 \mathrm{~V}$, increasing with the deflection produced in the midspan for both dosages. 
Figure 4. Relation between the load (kN) and the deflection (mm). (a) HM-25; (b) HM-40. Source: own elaboration.

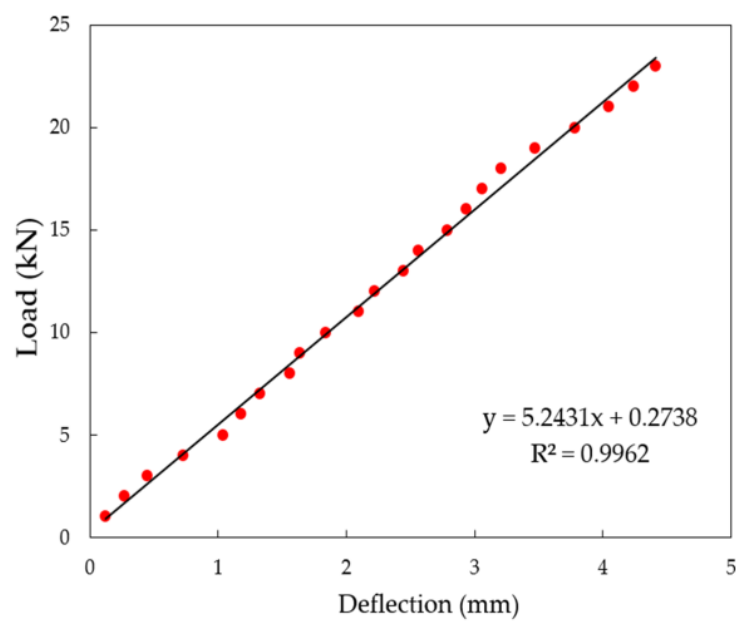

(a)

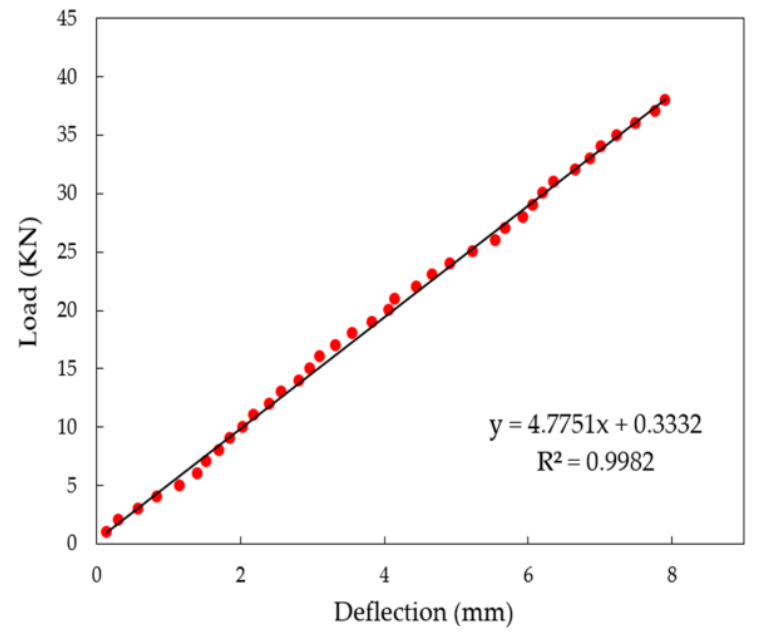

(b)

Figure 5. Relation between the load (kN) and the deflection (mm). (a) HM-25; (b) HM-40. Source: own elaboration.

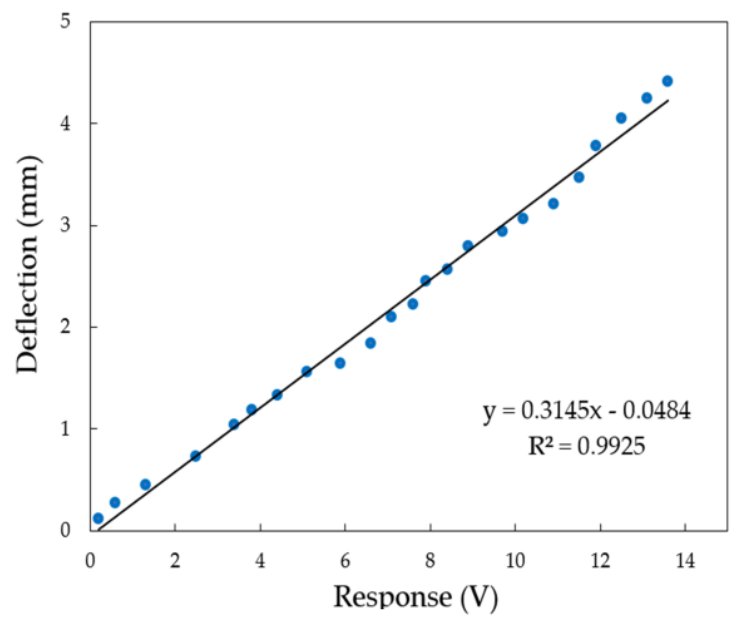

(a)

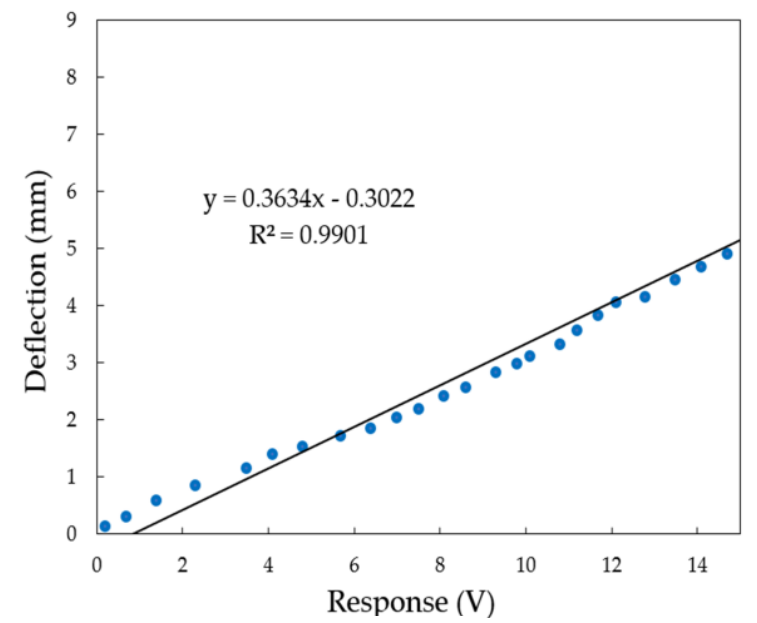

(b)

Figure 6 shows the final state of one of the samples after the flexural strength test and the position of the sensor adhered to the inferior part by the circuit placed on the definitive plate and the power source fabricated of $5 \mathrm{~V}$.

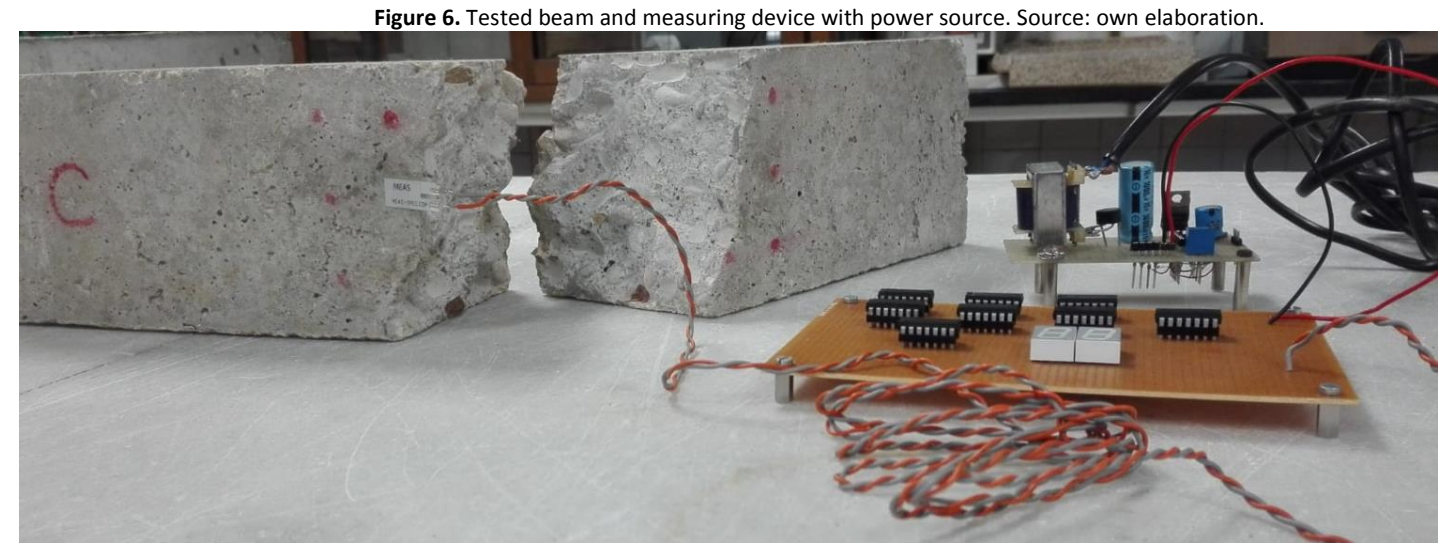

As it can be observed in Figure 6, the rupture of the beams produces in the midspan just in the point of load application. Both samples HM-25 and HM-40 start to crack on the inferior part after the flexural effort, that provokes the deflection of the sensor placed on the inferior part. It should be mentioned that the same test can be performed for reinforced concrete structures where more pronounced deflections would be obtained and higher response in voltage of piezoelectric sensor would be observed. 
This would allow its incorporation into the devices of data collection as for example ones based on Arduino platform, in a way that it would be possible to collect records of taken measurements studying evolution of deflection in the beam since its placing in service. For this, a previous calibration of sensors would be necessary, taking into consideration slabs and instant deflection produced after putting the structure into service that can distort the measurements and can be confused with the evolution of total deflection to which large duration loads have to be added that can provoke the collapse of concrete beams by overload.

\section{Conclusions}

Measuring device developed in this research presents a linear response to the deformation produced in concrete beams. Deflection variation with respect to the load is reflected into the response of the piezoelectric sensor in voltage situated in the midspan that allows to know in real time the state of deformation of the structure. Moreover, the response of the sensor in voltage presents a linear behaviour towards the applied load for both dosages HM-25 and HM-40. The maximum deflection was not more than $5 \mathrm{~mm}$ for the first one and no more than $8 \mathrm{~mm}$ for the second one.

Furthermore, one of the possible applications of this device could be using it as an alarm system in building under the risk of collapse that have to be monitored in real time. For this, it would be necessary to calibrate the sensor according to the performed laboratory tests over scale structures elaborated with the same materials. These systems can be used after their validation to control cracking and fissures in reinforced concrete structures, collecting the information received by the sensor after its deflection (Voutetaki et al., 2016). Moreover, it has reduced energy consume compared to other active commercial systems favouring its use in the construction reducing the cost.

Acknowledgements

The authors would like to thank to Vicente Martínez and Engerst Yedra for the collaboration and providing laboratories for the development of measuring system.

References

Ausanio, G., Barone, A.C., Hison, C., lannotti, V., Mannara, G., \& Lanotte, L. (2005). Magnetoelastic sensor application in civil buildings monitoring. Sensors and Actuators A, 123, 290-295. doi:10.1016/j.sna.2005.03.027.

Demi, A. Chao, W. Luo, H. \& Hong-ping, Z. (2018). Monitoring of the load-induced RC beam structural tension/compression stress and damage using piezoelectric transducers. Engineering Structures, 154, pp. 38-51. 10.1016/j.engstruct.2017.10.046.

García, A., Morán, F., \& Arroyo, J. C. (2011). Jiménez Montoya Hormigón Armado. Editorial Gustavo Gil, 15ąEdición, ISBN: 978-84-252-2307-5.

García, G., Simonin, J.M., Piau, J.M., Cottineau, L.M., Chupin, O., Momm, L., \& Mattar, A. (2017). Weigh in motion (WIM) sensor response model using pavement stress and deflection. Construction and Building, 156, 83-90, doi.org/10.1016/j.conbuildmat.2017.08.085

Gil, F., \& Mas-Guindal, A.J. (2015). Influence of accumulation of service concrete truss deformation effect of rigid enclosure. Anales de la Edificación, 1, 3, 49-53, doi: 10.20868/ade.2015.3137.

Karayannis, C.G., Voutetaki, M.E., Chalioris, C.E., Providakis, C.P. \& Angeli, G.M. (2015). Detection of flexural damage stages for RC beams using Piezoelectric sensors (PZT). Smart Structures and Systems, 15, 997-1018. doi.org/10.12989/sss.2015.15.4.997.

Kong, Q. Robert, R.H. Silva, P. \& Ho, Y.L. (2016). Cyclic Crack Monitoring of a Reinforced Concrete Column under Simulated Pseudo-Dynamic Loading Using Piezoceramic-Based Smart Aggregates. Applied Sciences, 6, 341; doi:10.3390/app6110341.

Lapko, A., \& Urbariski, M. (2015). Experimental and theoretical analysis of deflections of concrete beams reinforces with basalt rebar. Archives of Mechanical and Civil Engineering, 15, 1, 223-230, doi./10.1016/j.acme.2014.03.008.

Mohamed, A. (2017). Flexural behaviour and analysis of reinforced concrete beams made of recycled PET waste concrete. Construction and Building Materials, 155, 593-604, doi/10.1016/j.conbuildmat.2017.08.096.

Morón, C., García, A., \& Ferrández, D. (2014). New system for measuring impact vibration on floor decking sheets. Sensors, 14(5), 8895-8925; doi:10.3390/s140508895.

Payo, I., \& Feliu, V. (2014). Strain gauges based sensor system for measuring 3-D deflections of flexible beams. Sensors and Actuators A, 217, 81-94. doi.org/10.1016/j.sna.2014.06.014.

Providakis, C.P., Stefanaki, K. D., Voutetaki, M. E., Tsompanakis, Y., \& Stavroulaki, M. (2013). Damage detection in concrete structures using a simultaneously activated multi-mode PZT active sensing system: numerical modelling. Structure and Infrastructure Engineering, 10(11), doi.org/10.1080/15732479.2013.831908.

Real Decreto 1247/2008 (2008). Instrucción de Hormigón Estructural (EHE-08). BOE, 203, 35176-35178. 
Un, C.H., Sanjayan, J.G., San Nicolas, R. \& van Deventer, J.S.J. (2015). Predictions of long-term deflection of geopolymer concrete beams. Construction and Building Materials, 94, 10-19, doi: 10.1016/j.conbuildmat.2015.06.030.

UNE (2009a). UNE-EN 12350-2:2009. Testing fresh concrete - Part 2: Slump-test. AENOR.

UNE (2009b). UNE-EN 12390-2:2009. Testing hardened concrete - Part 2: Making and curing specimens for strength tests. AENOR.

UNE (2009c). UNE-EN 12390-5:2009. Testing hardened concrete - Part 5: Flexural strength of test specimens. AENOR.

Vignolo, G., Vázquez, J.A. (2012). Diseño, simulación y ensayo de un sensor de deformación paralelo de alta ganancia. Mecánica Computacional, 31, 3751-3763.

Voutetaki, M.E., Nikos, A. P., Georgia, A. \& Providakis, C.P. (2016). Investigation of a new experimental method for damage assessment of RC beams failing in shear using piezoelectric transducers. Engineering Structures, 114, pp. 226-240. 10.1016/j.engstruct.2016.02.014. 